\title{
Risk factors of hypertension in Expo South Sulawesi participants
}

\author{
Syahratul Aeni ${ }^{1}$, Nildawati ${ }^{2}$, Surahmawati ${ }^{3}$ \\ ${ }^{1,2}$ Bagian Epidemiologi Universitas Islam Negeri Alauddin \\ ${ }^{3}$ Bagian Administrasi Kebijakan Kesehatan Universitas Islam Negeri Alauddin
}

\begin{abstract}
Epidemiological transition is marked by changes in the pattern of disease and death which was originally dominated by infectious diseases that turn to non-communicable diseases, one of which is hypertension. In Indonesia, hypertension is a potential problem, in addition to its high prevalence, as well as its fatal diseases such as heart disease, stroke, kidney failure and others. The purpose of this study was to determine the risk factors that influence hypertension. This research used quantitative research with observational analytic approach and cross sectional study design. The population in this study was South Sulawesi expo participants. The sample in this study was 107 respondents with a purposive sampling method. The results of this study indicated that there was a significant relationship between family history of disease factors with hypertension but there was no significant correlation between the incidence of hypertension with some participant behavior such as smoking habits, lack of physical activity, less consumption of fruits and vegetables, and alcohol comsumtion. Although some trigger factors are not significant for hypertension, these factors can cause and worsen the occurrence of hypertension in the future. We suggest that expo participants always check their blood pressure routinely
\end{abstract}

Keyword: hypertention; risk factors; expo participants

\begin{abstract}
ABSTRAK
Transisi epidemiologi ditandai dengan perubahan pola penyakit dan kematian yang semula didominasi oleh penyakit menular yang beralih ke penyakit tidak menular, salah satunya Hipertensi. Di Indonesia hipertensi merupakan masalah yang potensial selain karena prevalensinya tinggi, juga penyakit yang diakibatkannya sangat fatal seperti penyakit jantung, stroke, gagal ginjal dan lain-lain.Tujuan penelitian ini adalah untuk mengetahui faktor risiko yang mempengaruhi penyakit hipertensi. Penelitian ini menggunakan jenis penelitian kuantitatif dengan pendekatan analitik observasional dan desain cross sectional study. Populasi pada penelitian ini peserta expo Sulawesi Selatan. Sampel pada penelitian ini adalah 107 responden dengan metode penarikan sampel purposive sampling. Hasil penelitian ini menunjukkan bahwa terdapat hubungan yang signifikan antara faktor riwayat penyakit keluarga dengan penyakit hipertensi namun tidak terdapat korelasi yang signifikan antara kejadian penyakit hipertensi dengan beberapa perilaku peserta seperti, kebiasaan merokok, kurangnya aktivitas fisik, kurang konsumsi buah dan sayur, serta konsumsi alkohol. Meskipun beberapa faktor pemicu tidak signifikan terhadap penyakit hipertensi namun faktor tersebut dapat menimbulkan serta memperparah terjadinya penyakit hipertensi dikemudian hari. Kami menyarankan kepada peserta expo untuk selalu rutin memeriksa tekanan darahnya
\end{abstract}

Kata kunci: hipertensi; faktor risiko; peserta expo

\section{PENDAHULUAN}

Hipertensi atau tekanan darah tinggi adalah peningkatan tekanan darah sistolik lebih dari $140 \mathrm{mmHg}$ dan tekanan darah diastolik lebih dari $90 \mathrm{mmHg}$ pada dua kali pengukuran dengan selang waktu lima menit dalam keadaan cukup istirahat/ tenang. Peningkatan tekanan darah yang berlangsung dalam jangka waktu lama (persisten) dapat menimbulkan kerusakan pada ginjal (gagal ginjal), jantung (penyakit jantung koroner) dan otak (menyebabkan stroke) bila tidak dideteksi secara dini dan mendapat pengobatan yang memadai (Sudoyo et al., 2009)

Data WHO 2015 menunjukkan seki- 
tar 1,13 miliar orang di dunia menderita hipertensi. Artinya, 1 dari 3 orang di dunia terdiagnosis menderita hipertensi, hanya $36,8 \%$ di antaranya yang minum obat. Jumlah penderita hipertensi di dunia terus meningkat setiap tahunnya, diperkirakan pada 2025 akan ada 1,5 miliar orang yang terkena hipertensi. Diperkirakan juga setiap tahun ada 9,4 juta orang meninggal akibat hipertensi dan komplikasi (Kementerian Kesehatan RI, 2015).

Menurut American Heart Association $\{\mathrm{AHA}\}$, penduduk Amerika yang berusia diatas 20 tahun menderita hipertensi telah mencapai angka hingga 74,5 juta jiwa, namun hamper sekitar 90-95\% kasus tidak diketahui penyebabnya. Hipertensi merupakan silent killer dimana gejala dapat bervariasi pada masing-masing individu dan hampir sama dengan gejala penyakit lainnya. Gejala-gejalanya itu adalah sakit kepala/ rasa berat di tengkuk, mumet (vertigo), jantung berdebar-debar, mudah Ielah, penglihatan kabur, telinga berdenging (tinnitus), dan mimisan. (Sudoyo et al., 2009)

Di Indonesia, berdasarkan data Riskesdas 2013, prevalensi hipertensi di Indonesia sebesar $25,8 \%$, prevalensi tertinggi terjadi di Bangka Belitung (30,\%) dan yang terendah di Papua (16,8\%). Sementara itu, data Survei Indikator Kesehatan Nasional (Sirkesnas) tahun 2016 menunjukkan pen- ingkatan prevalensi hipertensi pada penduduk usia 18 tahun ke atas sebesar 32,4\% (Kementerian Kesehatan RI, 2015).

Hipertensi merupakan penyebab paling umum terjadinya kardiovaskular dan merupakan masalah utama di negara maju maupun berkembang. Kardiovaskular juga menjadi penyebab nomor satu kematian di dunia setiap tahunnya. Menurut data Riskesdas 2013 penduduk Indonesia usia 15 tahun ke atas, sebesar 36,3\% merokok, 93,5\% kurang konsumsi buah dan sayur, 52,7\% konsumsi garam lebih dari 2 ribu $\mathrm{mg}$ /hari, $15,4 \%$ obesitas, dan $26,1 \%$ kurang aktifitas fisik (Kementerian Kesehatan RI, 2015).

Berdasarkan data Profil Kesehatan Provinsi Sulawesi Selatan tahun 2015 prevalensi hipertensi di Sulawesi Selatan sebesar $13,68 \%$ dengan jumlah kasus 142,571. Prevalensi tertinggi terjadidi Kabupaten Gowa dengan jumlah 27,514 kasus $(10,17 \%)$, dan yang terendah terjadi di Kota Palopo (0\%). Menurut data P2PTM dan Kesehataan Keluarga Dinas Kesehatan Provinsi Sulawesi Selatan tahun 2018 berdasarkan laporan rutin PTM Puskesmas di Kabupaten / Kota dalam rentang 6 bulan, prevalensi hipertensi diketahui tertinggi di kota Makassar sebanyak 4244 kasus dan terendah di kabupaten Luwu Timur, Tator dan Kota Palopo tidak ada kasus. Tujuan penelitian ini adalah untuk mengetahui faktor risiko yang mempengaruhi penyakit 
hipertensi pada peserta dagang di Sulawesi Selatan

\section{METODE PENELITIAN}

Jenis penelitian ini adalah penelitian kuantitaif dengan pendekatan penelitian analitik observasional yang menggunakan desain cross sectionla study untuk melihat faktor resiko hipertensi pada peserta Expo Sulsel. Populasi dalam penelitian ini yaitu pegawai instansi pemerintah dan pegawai dinas kesehatan kota/kabupaten Sulawesi Selatan yang melakukan pemeriksaan di posbindu PTM yaitu 126 responden. Besar sampel pada penelitian ini yaitu 107 responden yang memenuhi kriteria inklusi yaitu mengisi seluruh data yang terdapat dalam form pemeriksaan kesehatan. Metode penarikan sampel yang digunakan adalah purposive sampling.

Data sekunder diperoleh dari hasil pemeriksaan kesehatan yang dilakukan di posbindu PTM dalam acara EXPO Sulawesi Selatan. Data yang dikumpulkan pada penelitian ini yaitu umur, jenis kelamin, riwayat penyakit pada keluarga, kebiasaan merokok, sering melakukan aktivitas fisik, konsumsi buah dan sayur serta konsumsi alkohol. Analisis data yang dilakukan pada penelitian ini yaitu analisis univariat dan analisis bivariate.

\section{HASIL PENELITIAN}

Tabel 1 menunjukkan bahwa dari 107 sampel yang diteli terdapat 30 penderita hipertensi kelompok umur 30-39 tahun paling tinggi yaitu 10 responden $(9.3 \%)$ dan terendah pada kelompok umur 20-29 tahun yaitu 5 responden (4.7\%). Sedangkan berdasarkan jenis kelamin di dominasi oleh kelompok perempuan yaitu 25 responden $(23.4 \%)$ dan pada kelompok laki-laki hanya 5 responden $(4.7 \%)$.

Berdasarkan tabel 2 diperoleh hasil bahwa riwayat penyakit keluarga pada responden yang ditinjau dari lima penyakit yaitu hipertensi, jantung, stroke, asma, dan kolestrol. Jumlah responden yang memiliki riwayat penyakit hipertensi 4 responden $(3,71 \%)$ dan yang tidak memiliki riwayat hipertensi sebanyak 26 responden $(24,3 \%)$. Kebiasaan merokok terbagi dalam dua kategori yaitu ya dan tidak. Jumlah responden yang memiliki kebiasaan merokok 8 responden $(7,5 \%)$, dan yang tidak memiliki kebiasaan merokok sebanyak 22 responden (20,6\%). Jumlah responden yang kurang melakukan aktivitatas fisik sebanyak 24 responden (22.4\%) dan responden yang cukup melakukan aktivitas fisik sebanyak 6 responden 95.6\%). Jumlah responden yang kurang mengkonsumsi buah dan sayur sebanyak 8 responden (7,5\%) dan responden yang cukup mengkonsumsi buah dan sayur sebanyak 
22 responden (20,6\%). Sedangkan jumlah responden yang mengkonsumsi alcohol tidak ada dan responden yang tidak mengkonsumsi alcohol sebanyak 30 responden $(28 \%)$

Hasil penelitian pada tabel 3 menunjukkan hubungan hipertensi dengan riwayat penyakit hipertensi diperoleh nilai $\mathrm{p}$ value $0,008(\mathrm{p}<0,05)$ artinya terdapat hubungan yang signifikan antara penyakit hipertensi
$>0,05)$ artinya tidak ada hubungan antara kurang aktivitas fisik dengan penyakit hipertensi pada pegawai yang melakukan pemeriksaan di Posbindu PTM EXPO Dinas Kesehatan Provinsi Sulawesi Selatan. Hubungan Kurang Konsumsi Buah dan sayur. Diperoleh hasil bahwa nilai $\mathrm{p}$ value $0,237(\mathrm{p}>0,05)$ artinya tidak ada hubungan antara kurang konsumsi buah dan sayur dengan penyakit hipertensi pada pegawai

Tabel 1. Distribusi Karakteristik Responden Berdasarkan Penyakit Hipertensi

\begin{tabular}{|c|c|c|c|c|c|c|}
\hline \multirow{3}{*}{ Umur } & \multicolumn{4}{|c|}{ Hipertensi } & \multirow{2}{*}{\multicolumn{2}{|c|}{ Total }} \\
\hline & \multicolumn{2}{|c|}{$\mathrm{Ya}$} & \multicolumn{2}{|c|}{ Tidak } & & \\
\hline & $\bar{n}$ & $\%$ & $\overline{\mathrm{n}}$ & $\%$ & $\overline{\mathrm{n}}$ & $\%$ \\
\hline $20-29$ & 5 & 4.7 & 20 & 18.7 & 25 & 23.4 \\
\hline $30-39$ & 10 & 9.3 & 21 & 19.6 & 31 & 29.0 \\
\hline $40-49$ & 6 & 5.6 & 17 & 15.9 & 23 & 21.5 \\
\hline $50-59$ & 9 & 8.4 & 16 & 15.0 & 25 & 23.4 \\
\hline$>60$ & 0 & 0.0 & 3 & 2.8 & 3 & 2.8 \\
\hline Total & 30 & 28.0 & 77 & 72.0 & 107 & 100.0 \\
\hline Jenis Kelamin & $\mathrm{n}$ & $\%$ & $\mathrm{n}$ & $\%$ & $\mathrm{n}$ & $\%$ \\
\hline Laki - laki & 5 & 4.7 & 29 & 27.1 & 34 & 31.8 \\
\hline Perempuan & 25 & 23.4 & 48 & 44.9 & 73 & 68.2 \\
\hline Total & 30 & 28.0 & 77 & 72.0 & 107 & 100.0 \\
\hline
\end{tabular}

Sumber: Data Primer, 2018

dengan riwayat keluarga penyakit hipertensi. Hubungan Kebiasaan Merokok dengan penyakit Hipertensi. Diperoleh hasil bahwa nilai $p$ value $0,651(p>0,05)$ artinya tidak ada hubungan antara kebiasaan merokok dengan penyakit hipertensi pada pegawai yang melakukan pemeriksaan di Posbindu PTM EXPO Dinas Kesehatan Provinsi Sulawesi Selatan. Hubungan Kurang Aktivitas Fisik dengan penyakit Hipertensi Diperoleh hasil bahwa nilai $p$ value 0,371 ( $p$ yang melakukan pemeriksaan di Posbindu PTM EXPO Dinas Kesehatan Provinsi Sulawesi Selatan. Hubungan antara Konsumsi Alkohol dengan Penyakit Hipertensi diperoleh hasil bahwa nilai $p$ value 0,156 ( $p$ $>0,05)$ artinya tidak ada hubungan antara kebiasaan konsumsi alcohol dengan penyakit hipertensi pada pegawai yang melakukan pemeriksaan di Posbindu PTM EXPO Dinas Kesehatan Provinsi Sulawesi Selatan. 


\section{PEMBAHASAN}

Responden pada penelitian ini adalah peserta EXPO Sulsel yang di adakan di Posbindu Penyakit Tidak Menular Dinas Kesehatan provinsi Sulawesi Selatan tahun 2018. Berdasarkan data hasil penelitian di peroleh hasil bahwa sebagian besar responden berumur $\geq 30$ tahun. Hal ini sesuai dengan teori yang menyatakan bahwa hipertensi sering dijumpai pada orang beru- an besar responden yang hipertensi adalah perempuan $23,4 \%$. Hasil penelitian ini sejalan dengan penelitian yang dilakukan di wilayah kerja Puskesmas Petangi Kabupaten Bandung dengan pevalensi hipertensi pada perempuan lebih besar dari pada lakilaki, dengan persentase $28,6 \%$ pada lakilaki dan $71,4 \%$ pada perempuan. (Arifin et al., 2016)

Berdasarkan hasil penelitian ini dari 30 responden yang menderita hipertensi,

Tabel 2. Distribusi Faktor Risiko Penyakit Hipertensi

\begin{tabular}{|c|c|c|c|c|c|}
\hline \multirow{2}{*}{\multicolumn{2}{|c|}{ Faktor risiko }} & \multicolumn{4}{|c|}{ Hipertensi } \\
\hline & & \multicolumn{2}{|c|}{$\mathrm{Ya}$} & \multicolumn{2}{|c|}{ Tidak } \\
\hline & & $\mathrm{n}$ & $\%$ & $\mathrm{n}$ & $\%$ \\
\hline \multirow{2}{*}{ Hipertensi } & $\mathrm{Ya}$ & 4 & 3,7 & 1 & 0,9 \\
\hline & Tidak & 26 & 24,3 & 76 & 71 \\
\hline \multirow{2}{*}{ Kebiasaan merokok } & $\mathrm{Ya}$ & 8 & 7,5 & 24 & 22.4 \\
\hline & Tidak & 22 & 20,6 & 53 & 49.5 \\
\hline \multirow{2}{*}{ Kurang aktivitas fisik } & Kurang & 24 & 22.4 & 55 & 51.4 \\
\hline & Cukup & 6 & 5.6 & 22 & 20.6 \\
\hline \multirow{2}{*}{ Kurang konsumsi buah dan sayur } & Kurang & 8 & 7.5 & 30 & 28.0 \\
\hline & Cukup & 22 & 20.6 & 47 & 49.3 \\
\hline \multirow{2}{*}{ Konsumsi alkohol } & $\mathrm{Ya}$ & 0 & 0.0 & 5 & 4.7 \\
\hline & Tidak & 30 & 28.0 & 72 & 67.3 \\
\hline
\end{tabular}

Sumber: Data Primer, 2018

sia 30 tahun atau lebih. Dengan bertambahnya umur, risiko terjadinya hipertensi meningkat. Hipertensi bisa terjadi pada segala usia, namun paling sering dijumpai pada usia 30 tahun atau lebih. Hal ini disebabkan oleh perubahan alami pada jantung, pembuluh darah dan hormon. Apabila perubahan tersebut disertai faktorfaktor lain maka bisa memicu terjadinya hipertensi (Raihan,2014).

Hasil penelitian menunjukkan sebagi- didapatkan bahwa reponden yang positif menderita hipertensi dan memiliki riwayat keluarga menderita hipetensi adalah sebanyak 4 responden(3,7\%) pasien dan sisanya yaitu sebanyak 22 responden $(23,9 \%)$ pasien adalah responden yang positif menderita hipertensi tetapi tidak memiliki riwayat keluarga menderita hipertensi. Setelah dilakukan Uji statistik diperoleh nilai probabilitas ( $\mathrm{p}$ value) sebesar 0,008 dengan tingkat kesalahan 0,05 . hal ini 
membuktikan bahwa terdapat hubungan antara riwayat keluarga dengan kejadian hipertensi pada peserta Expo Sulsel.

Penelitian ini sejalan dengan penelitian yang dilakukan oleh Dajo (2016) yang dilakukan di Rumah Sakit Umum Daerah Noongan diperoleh hasil nilai $\mathrm{p}=$ menyebabkan hipertensi hingga menimbulkan tanda dan gejala (Asriati, 2014).

Hipertensi memilikikecendurungan untuk menurun pada generasi selanjutnya. Faktor resiko ini tidak dapat dihilangkan tetapi dapat diantisipasi sedini mungkin dengan rajin melakukan kontrol terhadap

Tabel 3. Hubungan Faktor risiko dengan kejadian Hipertensi

\begin{tabular}{|c|c|c|c|c|c|}
\hline & \multicolumn{2}{|c|}{ Hipertensi } & \multicolumn{2}{|c|}{ Total } & \multirow{2}{*}{$\mathrm{P}$} \\
\hline & $\mathrm{Ya}$ & Tidak & $\mathrm{n}$ & $\%$ & \\
\hline \multicolumn{6}{|c|}{ Riwayat keluarga Hipertensi } \\
\hline $\mathrm{Ya}$ & 4 & 1 & 5 & 4.7 & \multirow{3}{*}{0.008} \\
\hline Tidak & 26 & 76 & 102 & 95.3 & \\
\hline Total & 30 & 77 & 107 & 100 & \\
\hline \multicolumn{6}{|l|}{ Kebiasaan merokok } \\
\hline $\mathrm{Ya}$ & 8 & 24 & 32 & 29.9 & \multirow{3}{*}{0.651} \\
\hline Tidak & 22 & 53 & 75 & 70.1 & \\
\hline Total & 30 & 77 & 107 & 100 & \\
\hline \multicolumn{6}{|l|}{ Kurang aktivitas fisik } \\
\hline Kurang & 24 & 55 & 79 & 73.8 & \multirow{3}{*}{0.371} \\
\hline Cukup & 6 & 22 & 28 & 26.2 & \\
\hline Total & 30 & 77 & 107 & 100 & \\
\hline \multicolumn{6}{|c|}{ Kurang konsumsi buah dan sayur } \\
\hline Kurang & 8 & 30 & 38 & 35.5 & \multirow{3}{*}{0.237} \\
\hline Cukup & 22 & 47 & 69 & 64.5 & \\
\hline Total & 30 & 77 & 107 & 100 & \\
\hline \multicolumn{6}{|l|}{ Konsumsi alkohol } \\
\hline $\mathrm{Ya}$ & 0 & 5 & 5 & 4.7 & \multirow{3}{*}{0.156} \\
\hline Tidak & 30 & 72 & 102 & 95.3 & \\
\hline Total & 30 & 77 & 107 & 100 & \\
\hline
\end{tabular}

Sumber: Data Primer, 2018

0,001 yang berarti ada hubungan yang signifikan antara riwayat penyakit keluarga hipertensi dengan penyakit hipertensi. Asriati melaporkan bahwa faktor keturunan memiliki peran penting dan menjadi penentu seberapa besar kecenderungan orang untuk menderita hipertensi. Namun jika hal ini dibiarkan secara alamiah tanpa intervensi apapun, maka bersama lingkungannya akan tekanan darah di fasilitas kesehatan terdekat baik itu di Puskesmas maupun di Rumah Sakit dan menjaga pola hidup sehat.

Pada penelitian lain hal ini tidak sejalan dengan penelitianyang dilakukan oleh Tular (2015) yang dilakukan di Desa Tarabitan Kecamatan Likupang Barat Kabupaten Minahasa Utara diperoleh hasil nilai $\mathrm{p}=$ 1,000 yang berarti tidak terdapat hubungan 
yang signifikan antara penyakit hipertensi dengan riwayat keluarga hipertensi.

Berdasarkan hasil analisis univariat diperoleh hasil bahwa sebagian besar penderita hipertensi adalah bukan perokok (20,6\%). Selanjutnya, dianalis dengan uji bivariate dan didapatkan nilai signifikansi 0,651 hal ini berarti tidak terdapat hubungan yang signifikan antara kebiasaan merokok dengan penyakit hipertensi pada peserta EXPO Sulsel tahun 2018.

Hasil penelitian ini sejalan dengan penelitian yang telah dilakukan oleh Kurniasih (2013) yang dilakukan di Puskesmas Srondol Semarang diperoleh hasil nilai $\mathrm{p}=$ 0,057 yang artinya tidak terdapat hubungan yang signifikan antara faktor risiko kebiasaan merokok dengan penyakit hipertensi. Hasil penelitian lain yang sejalan dengan penelitian ini adalah penelitian yang dilakukan oleh Santosa (2016) yang dilakukan di Puskesmas Kenduruan, Kabupaten Tuban diperoleh hasil nilai $\mathrm{p}=1,000$ yang berarti tidaak terdapat hubungan yang signifikan antara faktor risiko kebiasaan merokok dengan penyakit hipertensi.

Namun penelitian ini tidak sejalan dengan penelitian yang dilakukan oleh $\mathrm{Da}-$ jo (2016) yang dilakukan di Rumah Sakit Umum Daerah Noongan diperoleh hasil nilai $\mathrm{p}=0,022$ yang berarti terdapat hubungan yang signifikan antara faktor risiko kebiasaan merokok dengan penyakit hipertensi. Analisis lanjut dari hasil penelitian riskesdas 2007 mendapatkan faktor merokok yang berisiko terhadap hipertensi adalah pernah merokok, yang artinya perilaku merokok dilakukan responden beberapa waktu sebelumnya. Hal ini menunjukkan pengaruh rokok terhadap hipertensi baru ditemukan setelah beberapa waktu kemudian. Risiko ini terjadi akibat zat kimia beracun yang dihisap melalui rokok yang masuk ke dalam aliran darah dapat merusak lapisan endotel pembuluh darah arteri dan mengakibatkan proses aterosklerosis dan tekanan darah tinggi. Merokok juga dapat meningkatkan denyut jantung dan kebutuhan oksigen otot jantung (Kurniasih, 2013).

Berdasarkan hasil analisis univariat diperoleh hasil bahwa 24 responden $(22,4 \%)$ kurang melakukan aktivitas fisik. Dan berdasarkan hasil analaisis diperoleh nilai $p$ value sebesar 0,371 yang berarti tidak terdapat hubungan yang signifikan antara faktor risiko kurang aktivitas fisik dengan penyakit hipertensi.

Hasil penelitian ini sejalan dengan penelitian yang dilakukan oleh Kurniasih (2013) yang dilakukan di Puskesmas Srondol Semarang diperoleh hasil nilai $\mathrm{p}=0,549$ yang berarti tidak terdapat hubungan yang signifikan antara faktor risiko kurang aktivitas fisik dengan penyakit hipertensi. Namun hasil ini tidak sejalan 
dengan penelitian yang dilakukan oleh Putri (2016) yang dilakukan Pada Pasien Rawat Jalan Di Poloklinik Interna Rumah Sakit Daerah Belitung diperoleh hasil nilai $\mathrm{p}=0,018$ yang berarti terdapat hubungan yang signifikan antara faktor risiko kurang aktivitas fisik dengan penyakit hipertensi.

Berdasarkan literatur, kurangnya aktifitas fisik meningkatkan risiko menderita hipertensi karena meningkatkan risiko kelebihan berat badan. Orang yang tidak aktif cenderung mempunyai frekuensi denyut jantung yang lebih tinggi sehingga otot jantungnya harus bekerja lebih keras tiap kontraksi. Makin keras dan sering otot jantung memompa, tekanan yang dibebankan pada arteri semakin besar. Hal tersebut kemungkinan juga disebabkan variabel level aktivitas fisik dipengaruhi oleh variabel lain yang lebih kuat sebagai faktor risiko hipertensi Kurniasih (2013).

Berdasarkan hasil penelitian yang telah dilakukan diperoleh hasil 8 responden (7,5\%) kurang menkonsumsi buah dan sayur dan 22 responden (20,6\%) kategori cukup dalam hal mengkonsumsi buah dan sayur. Setelah di analasisi di peroleh hasil nilai $p$ value $0,237(p>0,05)$ artinya tidak ada hubungan yang signifikan antara faktor risiko kurang konsumsi buah dan sayur dengan penyakit hipertensi.

Hasil penelitian ini tidak sejalan dengan penelitian yang telah dilakukan oleh
Anwar (2014) yang meneliti Konsumsi Buah Dan Sayur Serta Konsumsi Susu Sebagai Faktor Risiko Terjadinya Hipertensi Di Puskesmas Parman Kota Banjarmasin yang dalam penelitiannya diproleh hasil nilai $\mathrm{p}=0,000$ yang berarti ada hubungan yang signifikan terhadap konsumsi buah dan sayur dengan penyakit hipertensi.

Berdasarkan hasil analisis univariat diperoleh hasil bahwa tidak terdapat responden yang mengkonsumsi alcohol. Dan berdasarkan hasil analaisis diperoleh nilai $p$ value sebesar 0,156 yang berarti tidak terdapat hubungan yang signifikan antara faktor risiko kurang konsumsi alkohol dengan penyakit hipertensi.

Hasil penelitian ini sejalan dengan penelitian yang dilakukan oleh Santosa (2016) yang di lakukan di Puskesmas Kenduruan, Kabupaten Tuban diperoleh hasil nilai $\mathrm{p}=1,000$ yang bebrarti tidak terdapat hubungan yang signifikan antara faktor risiko kurang konsumsi alkohol dengan penyakit hipertensi. Hal ini sejalan dikarenakan pada penelitian yang dilakukan Santosa et al (2016) dari 75 responden hanya terdapat 1 responden yang mengkonsumsi alkohol, begitupun dengan hasil penelitian yang dilakukan peneliti dari 30 responden tidak terdapat satupun responden yang mengkonsumsi alkohol.

Penelitian lain yang sejalan dengan penelitian ini adalah peneltian yang dil- 
akukan oleh Lu (2015) yaitu penelitian kohor yang dilakukan tahun 2004 - hingga 2012 di the Health Management Center of the Third Xiangya Hospital, Changsha, China. Hasil penelitian yang diperoleh nilai $\mathrm{p}=0,05$ yang berarti tidak terdapat hubungan yang signifikan antara faktor risiko kurang konsumsi alkohol dengan penyakit hipertensi. Ada berbagai pendapat mengenai apakah alkohol dapat meningkatkan tekanan darah. Konsumsi alkohol merupakan faktor risiko penyakit kardiovaskular, mirip dengan hipertensi, dan sebagian pedoman menyarankan berhenti konsumsi alkohol. Beberapa ahli telah menyarankan untuk tidak mengkonsumsi alcohol secara berlebihan, karena bila dikonsumsi dalam jumlah besar alcohol memiliki efek meningkatkan tekanan darah.

Alquran dan hadis merupakan pegangan hidup manusia. Didalamnya terdapat petunjuk tentang berbagai aspek kehidupan manusia, termasuk kesehatan. Dalam surat Al-Qaaf ayat 16 yang terjemahnya:

"Dan sesungguhnya Kami telah menciptakan manusia dan mengetahui apa yang dibisikkan oleh hatinya, dan Kami lebih dekat kepadanya daripada urat lehernya."

Urat leher yang dimaksud dalam ayat ini adalah pembuluh darah yang terdapat dileher. Dalam sebuah hadis dijelaskan oleh Shafiyah binti Huyay bahwa
Rasulullah saw. bersabda :

"Sesungguhnya setan itu berjalan dalam tubuh anak Adam melalui peredaran darah dalam tubuhnya". (HR.Muslim).

Hipertensi atau tekanan darah tinggi merupakan salah satu penyakit yang disebabkan oleh kelainan pada peredaran darah atau arteriosclerosis.

\section{KESIMPULAN}

Pada penelitian ini dapat disimpulkan bahwa terdapat satu variabel yang memiliki hubungan dengan penyakit hipertensi yaitu faktor risiko riwayat keluarga dengan kejadian penyakit hipertensi. Sedangkan terdapat empat variabel yang tidak memiliki hubungan yang signifikan dengan penyakit hipertensi yaitu faktor risiko kebiasaan merokok, kurang aktivitas fisiki, kurang konsumsi buah dan sayur dan konsumsi alkohol.

\section{SARAN}

Peneliti menyarankan kepada peserta Expo yang menderita hipertensi untuk melakukan pengontrolan tekanan darah secara rutin. Disarankan kepada petugas kesehatan untuk melakukan promosi kesehatan atau pencegahan hipertensi. Perlu adanya penelitian lanjutan dalam jumlah sampel yang lebih besar dan variabel yang lebih bervariasi. 


\section{DAFTAR PUSTAKA}

Arifin, M. H. B. M., Weta, I. W., \& Ratnawati, N. L. K. A. (2016). Factors Related to the Occurrence of Hypertension in the Elderly Group in the Work Area of the UPT Puskesmas Petang I Bandung Regency in 2016. E-Jurnal Medika, 5 (7), 1-23. http://ojs.unud.ac.id/index.php/eum

Anwar. (2014). Konsumsi Buah dan Sayur Serta Konsumsi Susu Sebagai Faktor Risiko Terjadinya Hipertensi di Puskesmas Parman Kota Banjarmasin.Jurnal Skala Kesehatan.5(01)

Asriati. Wahiduddin, Rismayanti. 2014. Faktor Risiko Riwayat Keluarga, Status Gizi Dan Riwayat Diabetes Melitus Terhadap Kejadian Hipertensi Lansia Di Wilayah Kerja Puskesmas Pattingalloang.

Dajo, P. C., Kandou, G. D., \& Punuh, M. I. (2016). Hubungan Kebiasaan Merokok, Stres, Riwayat Keluarga Dengan Kejadian Hipertensi Pada Pasien Di Rumah Sakit Umum Daerah Noongan. Artikel Publikasi Ilmiah, 1-8.

Dinas Kesehatan Provinsi Sulawesi Selatan. (2015). Profil Kesehatan Sulawesi Selatan Tahun 2016, Makassar

Kementerian Kesehatan RI. (2015).Riset Kesehatan Dasar. Badan Penelitian Dan Pengembangan Kesehatan Kementrian RI

Kurniasih, I., \& Setiawan, M. R. (2013). Analisis Faktor Risiko Kejadian Hipertensi Di Puskesmas Srondol Semarang Periode Bulan September - Oktober 2011. Jurnal Kedokteran Muhammadiyah $V$, , 54-59.
Lu, Y., Lu, M., Dai, H., Yang, P., Smith-gagen, J., Miao, R., \& Zhong, H. (2015). Lifestyle and Risk of Hypertension : Follow-Up of a Young Pre-Hypertensive Cohort. International Journal of Medical Sciences, 12(Cvd), 80-85. https://doi.org/10.7150/ijms.12446

Putri, I. A., Kaunang, W. P. J. And Kepel, B. J. (2016) 'Hubungan Antara Aktivitas Fisik, Kebiasaan Merokok, Dan Riwayat Keluarga Dengan Kejadian Hipertensi Pada Pasien Rawat Jalan Di Poloklinik Interna Rumah Sakit Daerah Belitung', Artikel Publikasi Ilmiah.

Raihan Ln, Erwin, Dewi Ap. Faktor-Faktor Yang Berhubungan Dengan Kejadian Hipertensi Primer Pada Masyarakat Di Wilayah Kerja Puskesmas Rumbai Pesisir. [Skripsi]. Pekanbaru; Universitas Riau. 2014.

Santosa, L. H. K., Chasani, S., \& Pramudo, S. G (2016). Faktor Risiko Kejadian Hipertensi di Puskesmas Kenduruan, Kabupaten Tuban (Doctoral dissertation, Diponegoro University)

Sudoyo AW, Setiyohadi B, Alwi I, Simadibrata M, Setiati S. Buku ajar ilmu penyakit dalam jilid ii. Edisi V. Jakarta: Interna Publishing; 2009

Tular, G. J., Ratag, B. T., \& Kandou, G. D. (2017). Hubungan Antara Aktivitas Fisik, Riwayat Keluarga Dan Umur Dengan Kejadian Hipertensi Di Desa Tarabitan Kecamatan Likupang Barat Kabupaten Minahasa Utara. Artikel Publikasi Ilmiah, 1-6. 